\title{
Threshold, optimum and critical geoenvironmental conditions for burrowing activity of sand bubbler crab, Scopimera globosa
}

\author{
Shinji Sassa*, Yoichi Watabe
}

Soil Mechanics and Geo-Environment Division, Port and Airport Research Institute, 3-1-1 Nagase, Yokosuka 239-0826, Japan

\begin{abstract}
The role of physical processes in sediments in the response of macroinfauna remains largely unknown, in contrast to the role of waves and swash conditions. This study was motivated by our recent finding on the physics involved in intertidal sediments and aims to explore the link between geophysics and ecology. Field observations were performed on an intertidal sand flat on the east coast of Tokyo Bay, Japan. The results indicate that the development of suction (s), i.e. negative pore water pressure relative to atmospheric air pressure, was closely linked to the behaviour of the sand bubbler crab Scopimera globosa (Crustacea: Ocypodidae) and was the trigger responsible for the onset of its burrowing activity. Three series of laboratory burrowing experiments were performed by simulating the relevant geophysical environment prevailing in the intertidal flat sediment. The results demonstrate that the burrowing performance of $S$. globosa depended strongly on the state of $s$ in association with the groundwater level. Notably, under a given sediment porosity, burrows started to develop and reached peak depth when $s$ was present initially, but declined rapidly with increased $s$. The effective cohesion and stiffness of the sediment produced by the $s$ were responsible for the manifestation of the threshold, optimum, and critical conditions for the development of the burrows. The present results imply that the $s$ and related geophysical environmental conditions may have an important contribution to the natural selection of habitats of macroinfauna in intertidal zones
\end{abstract}

KEY WORDS: Burrowing · Suction · Groundwater · Ocypodidae $\cdot$ Scopimera globosa $\cdot$ Laboratory experiments $\cdot$ Intertidal flat · Tokyo Bay

Resale or republication not permitted without written consent of the publisher

\section{INTRODUCTION}

Crabs that live in intertidal zones, such as members of the family Ocypodidae, dig burrows in sediment and often produce balls of sand on the exposed surface of the sediment. The burrows are essential and serve several purposes (Warner 1977). They allow the crabs to breathe air and to escape from predators. They protect the crabs from severe hydro-meteorological forcing due to tidal cycles, ranging from heat irradiation and winds during the period of exposure at low tides, to waves and currents during the period of submergence at high tides. Furthermore, the burrows function as a base for various kinds of basic living activities, such as feeding (e.g. Altevogt 1955), breeding (Christy 1987, Koga et al. 1993), and territorial behaviour (e.g. Zucker 1977). Most of these activities take place during periods of exposure.

Burrowing performance may thus be an important factor in determining the distribution of species through burrow density (Icely \& Jones 1978, Wada 2000), and in forming the macroinfaunal community of intertidal zones (Dugan et al. 2004). The burrowing performance of individual species may be affected by body size (Dugan et al. 2000), sediment grain size (Botto \& Iribarne 2000, Nel et al. 2001), temperature associated with physiological function (Donn \& Els 1990, Eshky et al. 1995), and intertidal morphodynam- 
ics in relation to swash climate (Brazeiro 2005). However, considering that burrowing itself represents physical action in sediments, the influence of geophysical state, such as sediment stiffness, on burrowing performance could be great. Despite its potential significance, the role of geophysical conditions in affecting burrowing performance remains largely unknown, in contrast to the role of wave and swash conditions that are manifested by the physical state of fluids (McLachlan 1990, McLachlan et al. 1993). This situation may stem from the lack of general understanding of the physical processes involved in intertidal sediments.

Recently, Sassa \& Watabe (2007) demonstrated that suction $(s)$, i.e. negative pore water pressure relative to atmospheric air pressure, plays a substantial role in controlling the geophysical environments of habitats with diverse infaunal activity. Building sand castles or boring a tunnel on a sand beach readily reveals the peculiar behaviour of $s$ between sand grains when they get wet. Indeed, $s$ develops above groundwater level in an exposed sandy sediment, even though $s$ is zero at the groundwater level. Sassa \& Watabe (2007) showed that the geophysical environmental conditions, such as voids, stiffness, and surface shear strength, of intertidal flat sediments are of unsteady nature in space and time, and depend largely on the state of $s$ in association with the groundwater level.

The present study explores the link between geophysics and ecology. Specifically, we studied the geophysical mechanisms underlying burrowing activity through field observations, as well as laboratory experiments in which the relevant geophysical environmental conditions were simulated and varied, and we observed the associated crab activity. For this purpose, we used the sand bubbler crab Scopimera globosa (Crustacea: Ocypodidae). Our controlled laboratory experiments gave rise to the manifestation of characteristic crab responses to the geophysical environment, revealing threshold, optimum, and critical geoenvironmental conditions for the burrowing activity of $S$. globosa.

\section{MATERIALS AND METHODS}

Field observations. Field observations were performed on the Banzu sand flat (Kuwae et al. 2003, Sassa \& Watabe 2007), on the east coast of Tokyo Bay, Japan. Scopimera globosa are the most common crabs in the intertidal zones of this flat. Other species of macroinfauna there include bivalves (Ruditapes philippinarum, Mactra chinensis, and Solen strictus), the mud shrimp Upogebia major and the ghost shrimp Callianassa japonica. The sediment is composed of fine-grained sand with median grain diameters $D_{50}=$ 0.17 to $0.23 \mathrm{~mm}$ and also contained silt and clay (grain diameters $<0.075 \mathrm{~mm}$ ), which together constituted, at most, $8 \%$ of total sediment.

The $s$, groundwater level, and burrowing activity of Scopimera globosa were continuously observed during 2 periods of exposure at the flat on May 25 and 26, 2005. The times corresponded to those of spring tides, with a tidal range of $1.9 \mathrm{~m}$.

$s$ refers the tension of moisture in the sediment (Bear 1979) and is defined as:

$$
s=u_{\mathrm{a}}-u_{\mathrm{w}}
$$

where $u_{\mathrm{a}}$ is the atmospheric air pressure and $u_{\mathrm{w}}$ is the pore water pressure in the sediment.

In order to look at the onset and progress of burrowing activity, we counted the number of groups of sand balls over time that individual crabs brought to the surface as a measure for their burrowing activity. These sand balls are larger than those the crabs produce when feeding at the sediment surface. For the observations, we chose level, $3 \mathrm{~m} \times 3 \mathrm{~m}$ sections of intertidal flat with similar rates of $s$. $s$, as well as groundwater level, was measured using tensiometers (Sassa \& Watabe 2007). The accuracy of the tensiometers was $\pm 0.01 \mathrm{kPa}( \pm 1 \mathrm{~mm}$ depth$)$.

The intertidal flat sediment remained saturated during the exposure periods; thus, there was a linear relationship between $s$ and groundwater level (Sassa \& Watabe 2007).

Burrowing experiments. The sediment and Scopimera globosa used for the burrowing experiments were taken from the Banzu flat described above. We examined the influence on burrowing performance of $s$, void state, and stiffness of the sediment. The void state of the sediment is represented by void ratio $e_{\text {, }}$ which is related to the sediment porosity $n$ :

$$
n=\frac{e}{1+e}
$$

The sediment relative density $\left(D_{\mathrm{r}}\right)$ denotes the sediment packing state:

$$
D_{\mathrm{r}}=\frac{e_{\max }-e}{e_{\max }-e_{\min }}
$$

For a given sediment, the maximum void ratio $e_{\max }$ represents the loosest possible packing, and the minimum void ratio $e_{\min }$ represents the densest possible packing (Taylor 1948). Thus, $D_{\mathrm{r}}$ is a normalized index by which to assess the packing states of sandy sediments.

The stiffness of the surface sediment can be represented by the vane shear strength (VSS) (Amos et al. 1988, Sassa \& Watabe 2007). VSS indicates the resistance of the surface sediment to shearing that may occur from the action of waves and currents, and also from the burrowing action of crabs. 


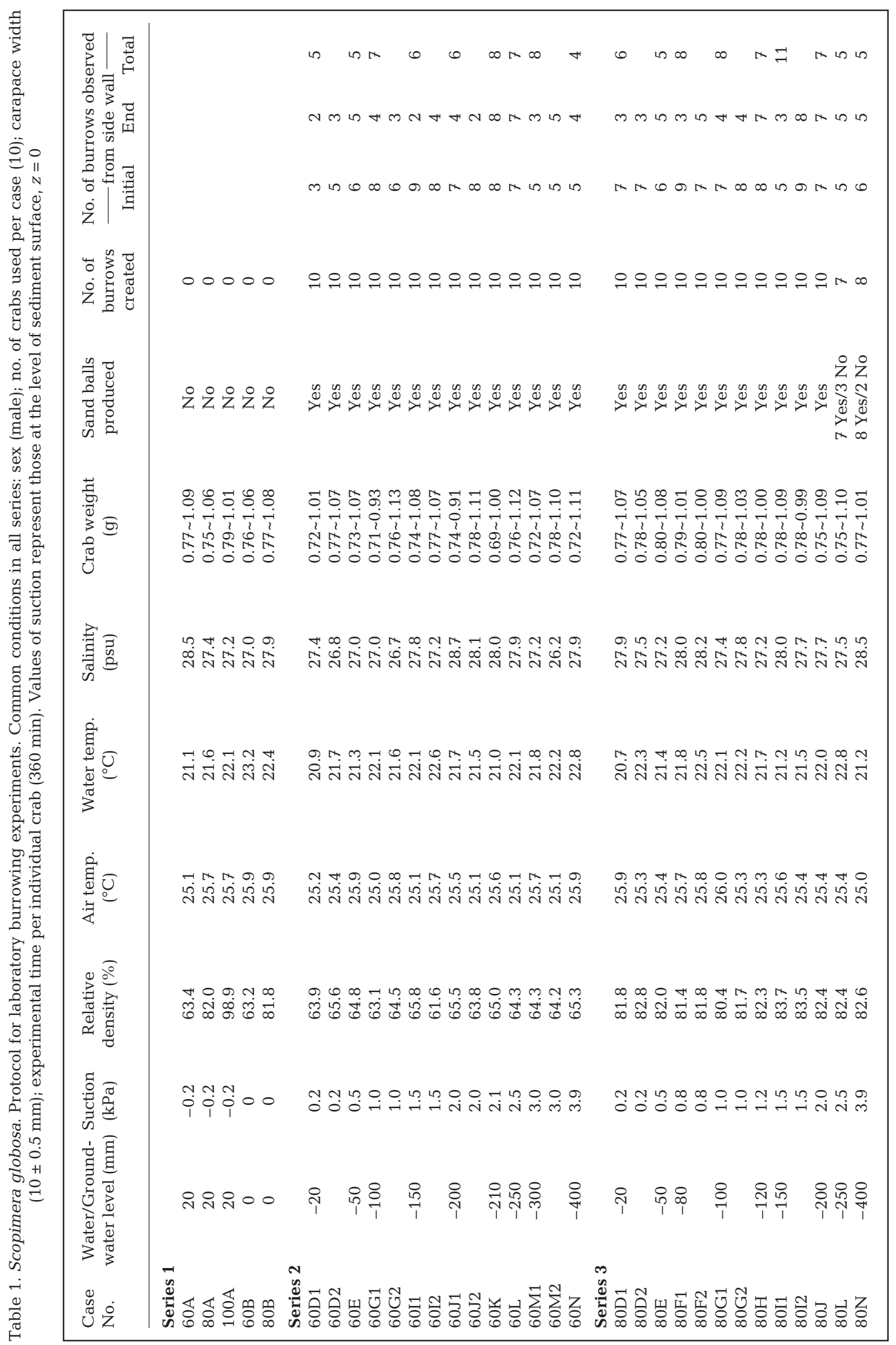



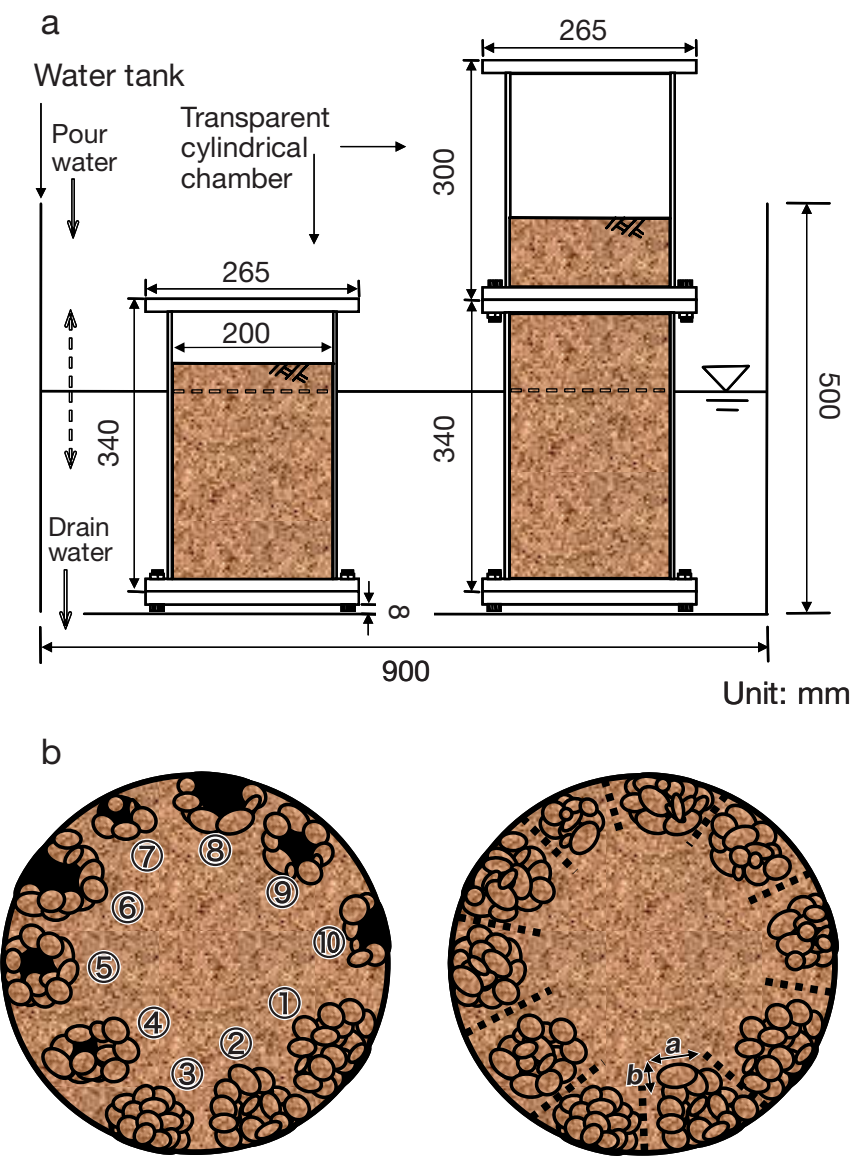

Fig. 1. Scopimera globosa. (a) Transparent cylindrical chambers used for burrowing experiments. The deeper chamber was used only for 2 cases, $60 \mathrm{~N}$ and $80 \mathrm{~N}$ (see Table 1). (b) Top views of burrowing experiments: (left) immediately after 10 crabs were introduced one at a time from 1 to 10 , and (right) some time later (e.g. $1 \mathrm{~h}$ ). $a, b$ : major and minor axes of sand ball diameters, respectively
VSS depends both on $s$ and $D_{\mathrm{r}}$, whose interrelationships are summarized in Appendix 1.

Three series of experiments, 32 cases in total (Table 1), were performed by prescribing the absence of $s$ in Series 1, and by changing $s$ from 0.2 to $3.9 \mathrm{kPa}$ at 2 different sediment relative densities $D_{\mathrm{r}}=62 \%$ to $66 \%$ in Series 2, and $D_{\mathrm{r}}=80$ to $84 \%$ in Series 3. For each case, we used 10 male Scopimera globosa with carapace widths of $10 \mathrm{~mm}$. With reference to Table 1, their individual weights ranged from 0.7 to $1.1 \mathrm{~g}$, and the mean individual weight was essentially constant, at 0.86 to $0.9 \mathrm{~g}$ in each case. In all experiments, the air temperature, water temperature, and salinity of the water and pore water were kept essentially constant at $25^{\circ} \mathrm{C}, 21$ to $23^{\circ} \mathrm{C}$, and 26 to $29 \mathrm{psu}$, respectively. The crabs were maintained in standing water at the above temperatures and salinity for over 1 mo prior to the experiments to ensure that any endogenous physiological rhythms were abolished (McGaw 2005).

In each case, we first prepared a cylindrical sediment deposit (Fig. 1a) by following the procedures of Sassa \& Watabe (2007). We then put the 10 Scopimera globosa, one at a time, around the edge of the circular surface of the sediment (Fig. 1b). In most cases, the crabs immediately started digging, i.e. they first produced sand balls and removed them from the sediment, thus creating burrows in the sediment. All of this behaviour was consistently observable from above the sediment surface; through the transparent side wall of the chamber the progress of the burrowing activity was observed in detail for a period of $6 \mathrm{~h}$ for each crab.

Side views of the burrowing experiments are schematically shown in Fig. 2a. We identified 3 different types of visible burrows (Types 1, 2, and 3) and 2 situations where no burrows were created (Types 4
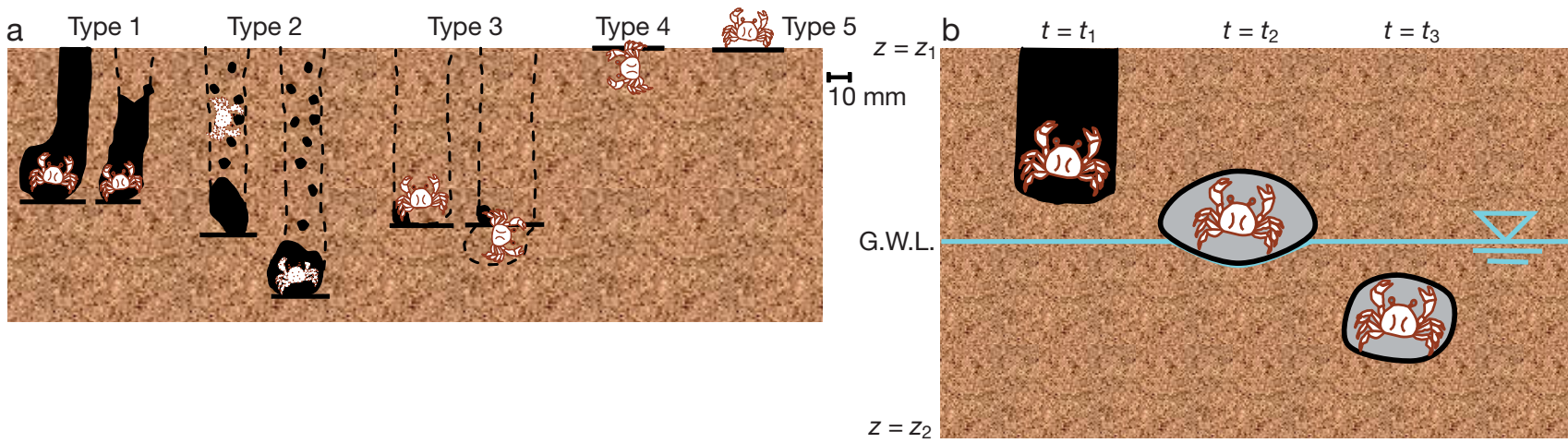

Fig. 2. Scopimera globosa. (a) Burrowing experiments with 3 different types of visible burrows (Types 1, 2, and 3) and 2 situations where there were no burrows (Types 4 and 5). Types 1,2, and 3 correspond to the cases where suction was present. Type 4 corresponds to the cases where suction was absent. Type 5 corresponds to the cases of excessive sediment stiffness from high suction and the dense sediment packing. Solid line represents the corresponding depth of the burrow identified at a given time. (b) Observed transition from the burrow to a closed cavity and its subsequent downward progression at the vicinity of the groundwater level (G.W.L.) 
and 5). Types 1, 2, and 3 correspond to cases where $s$ was present. Type 4 corresponds to cases where $s$ was absent. Type 5 corresponds to cases where the sediment stiffness exceeded a limit arising from high $s$ and the dense sediment packing state. For each type, the solid line in Fig. 2a represents the corresponding depth of the burrow identified at a given time.

The burrow depth occasionally reached the groundwater level, as illustrated in Fig. 2b. In these cases, the bottom of the burrow was slightly above the groundwater level at time $t=t_{1}$. The crab inside the burrow would then dig until reaching groundwater level and create a closed cavity around itself containing entrapped air by pasting sand balls above itself at time $t=t_{2}$. The crab then continued digging until the cavity was below the groundwater level at time $t=t_{3}$.

Some typical examples of the measured burrow depths with time are shown in Fig. 3. It can be seen that the burrow depths increased with time and eventually reached the final depth $(D)$ at time $T$, where $T$ denotes the amount of time it took a given crab to finish its burrow. Sometimes the burrows became invisi-
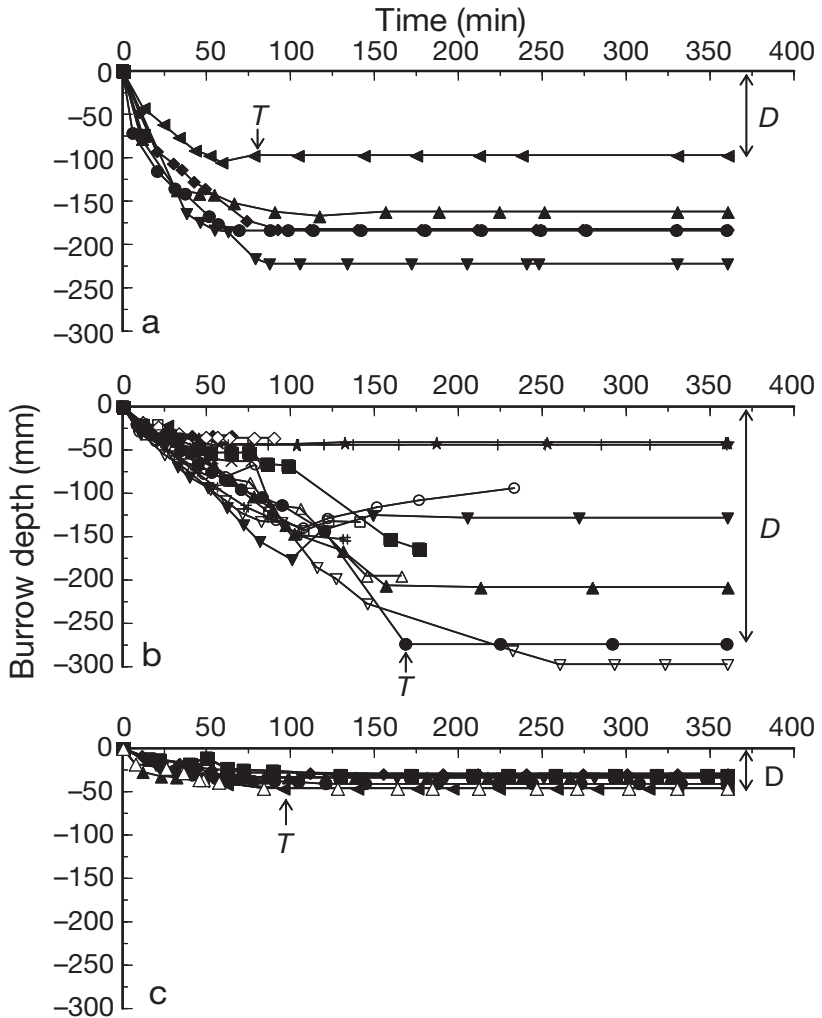

Fig. 3. Scopimera globosa. Measured burrow depths with time in (a) Case No. 60E (suction $0.5 \mathrm{kPa}, D_{\mathrm{r}}=64.8 \%$ ), (b) Case Nos. 60J1 and 60J2 (suction $2 \mathrm{kPa}, D_{\mathrm{r}}=65.5 \%$ [J1] and $63.8 \%$ [J2]), and (c) Case No. 80J (suction $2 \mathrm{kPa}, D_{\mathrm{r}}=82.4 \%$ ). $D$ : final depth of the burrow developed by an individual $\mathrm{crab} T$ : burrow formation time ble during the course of the experiment. In those cases, we stopped observation and repeated the experiment again; if there was any crab that had reached the bottom of the chamber, it was not counted to eliminate the effect of space constraints in the burrowing experiment.

We investigated the burrowing velocity $(-D / T)$, the burrow formation time $T$, and $D$ for each crab whose burrowing activity was consistently observed during the entire $6 \mathrm{~h}$ period of the experiment.

After completing the experiment, we sampled the sand balls produced and measured their major and minor axes (Fig. 1b).

\section{RESULTS}

\section{Field observations}

The variation of the groundwater level at the field observation sites caused dynamics changes in the $S$ states of the sediment (Fig. 4). Namely, $s$ developed initially at the uppermost sediment layer $(z=-10 \mathrm{~mm})$
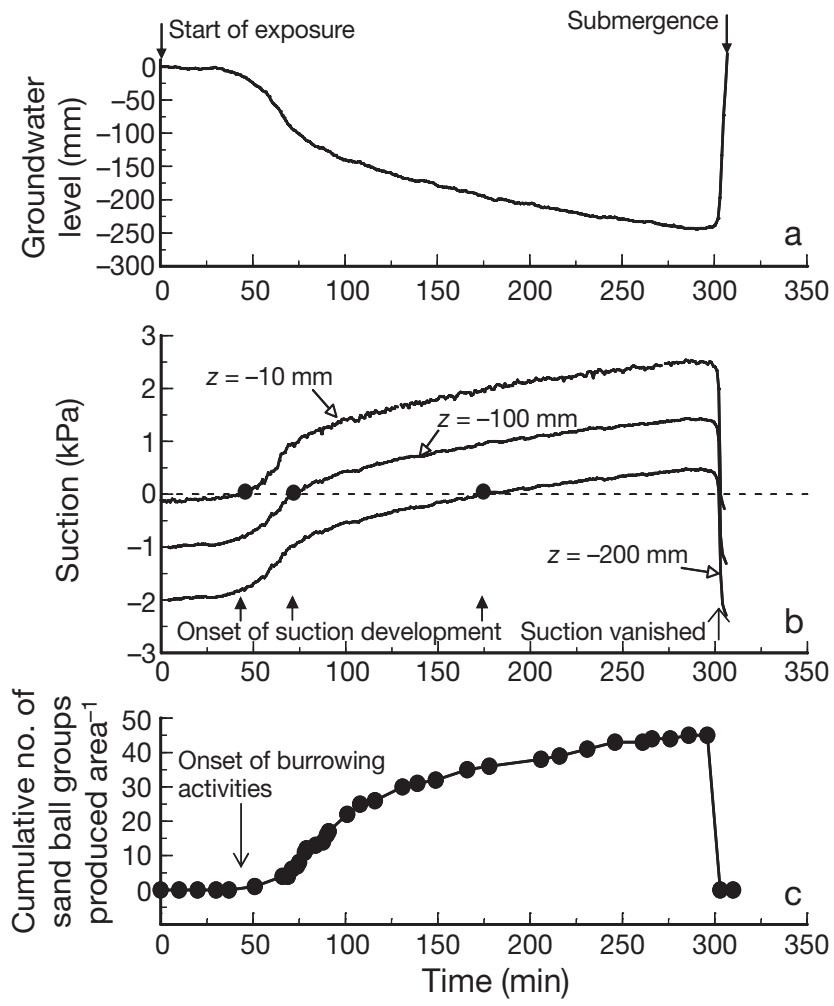

Fig. 4. Scopimera globosa. Results of field observations on (a) groundwater level, (b) suction, and (c) burrowing activity. In order to look at the onset and progress of burrowing activity, we counted the number of groups of sand balls over time that individual crabs brought to the surface as a measure for their burrowing activity 
about 50 min after exposure and then at deeper depths $(z=-100 \mathrm{~mm}$ and $-200 \mathrm{~mm})$ with the downward progress of the groundwater level. Upon submergence, the $s$ became negative and thus vanished.

Crab burrowing activities were closely associated with the variation of $s$ in the sediment. In particular, the onset of the burrowing activities coincided with the onset of $s$ development in the sediment. This strongly suggests that the crabs took advantage of the effective cohesion produced by the presence of $S$, which enabled burrowing activity in the sandy sediment that previously had no inherent cohesion. Indeed, the observed total collapse of the sand balls on the sediment surface upon submergence indicates that the sandy sediment cannot support itself in the absence of $s$. The same general behaviour of the burrowing activity in relation to the $s$ dynamics was observed during the exposure periods on both days.

Overall, the results of the field observations described above demonstrated that the initial development of $s$ was the trigger responsible for the onset of burrowing activity. In addition, there was a close link between the progress of the burrowing activity and the state of the $s$ in the sediment.

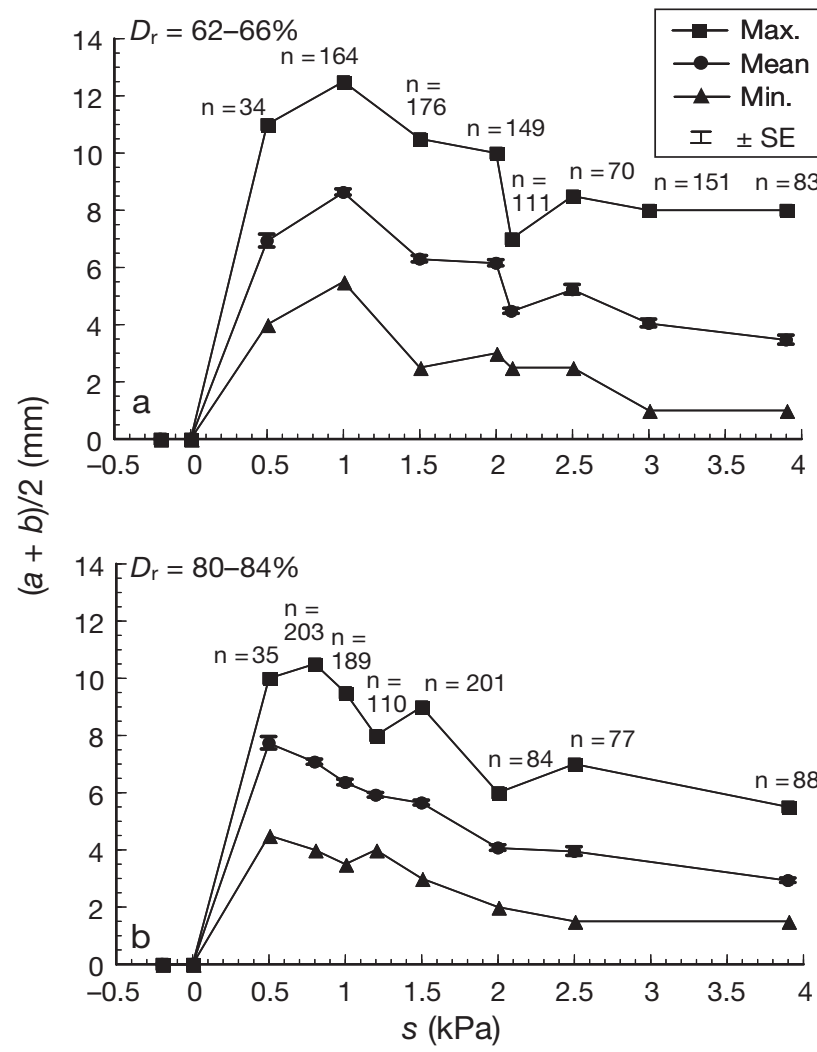

Fig. 5. Scopimera globosa. Measured diameters of the sand balls produced $((a+b) / 2$, where $a$ is the major axis and $b$ is the minor axis) versus suction $(s)$ for 2 different sediment relative densities, (a) $D_{\mathrm{r}}=62$ to $66 \%$ and (b) $D_{\mathrm{r}}=80$ to $84 \%$

\section{Burrowing experiments}

In all cases where the effect of the absence of $s$ on the burrowing activity was examined, there were no sand balls and no burrows. The crabs simply hid beneath the sediment surface at the beginning of the experiment and remained there for the subsequent $6 \mathrm{~h}$ period of the experiment. Since this series included the cases where the sediment was exposed, but $s$ was absent, we can readily exclude the possibility that the crabs did not form burrows due to their respiratory requirement in water. Thus, the results indicate that the crabs could not create burrows without the contribution of $s$, and therefore could only remain in the surface sediment.

Once $s$ was present in the sediment, sand balls were produced (Fig. 5) and burrows were created (Fig. 6). Notably, under $D_{\mathrm{r}}=62$ to $66 \%$, the burrow depths developed significantly deeper at low $s$ (e.g. 0.2 to $2 \mathrm{kPa}$ ) than at high $s$ (e.g. 2.1 to $3.9 \mathrm{kPa}$ ) (MannWhitney $U$-test, $\mathrm{p}<0.0001)$. This also proved to be the case for the higher density $D_{\mathrm{r}}=80$ to $84 \%$, under which the distinctive $s$ ranges were different such that low $s$ were between 0.2 and $1 \mathrm{kPa}$, and high $s$ were

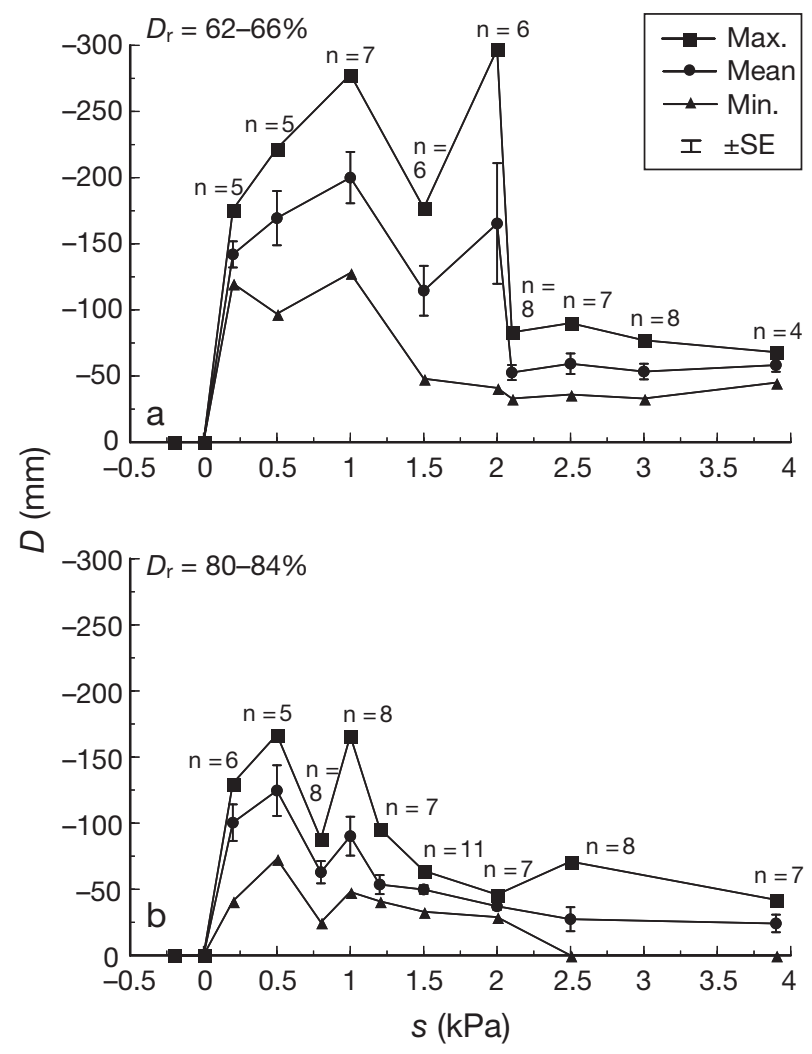

Fig. 6. Scopimera globosa. Measured final depths of the burrows $(D)$ versus suction $(s)$ for 2 different sediment relative densities: (a) $D_{\mathrm{r}}=62$ to $66 \%$ and (b) $D_{\mathrm{r}}=80$ to $84 \%$ 
between 1.2 and $3.9 \mathrm{kPa}(\mathrm{p}<0.0001)$. However, the developed burrow depths under the higher density $\left(D_{\mathrm{r}}=80\right.$ to $\left.84 \%\right)$ were significantly shallower than those under $D_{\mathrm{r}}=62$ to $66 \%(\mathrm{p}<0.0001)$.

The mean sand ball diameters $(a+b) / 2$ (where $a$ is the major axis and $b$ is the minor axis), $-D / T$, and $T$ versus $s$ for the 2 different densities, $D_{\mathrm{r}}=62$ to $66 \%$ and $D_{\mathrm{r}}=80$ to $84 \%$, are compared in Fig. 7. With increasing $s$, the sand ball diameters became smaller and the burrowing velocities became lower. Under the higher density $D_{\mathrm{r}}=80$ to $84 \%$, the sand ball diameters were marginally smaller and the burrowing velocities were significantly lower than those exhibited under $D_{\mathrm{r}}=62$ to $66 \%$ for the entire range of $s$ (Paired $t$-test, $\mathrm{p}=0.041$ for the diameters, $\mathrm{p}=0.0016$ for the velocities). By contrast, there were insignificant differences ( $\mathrm{p}=0.15)$ in $T$, which was less than $3 \mathrm{~h}$ in almost all cases.

The mean $D$ versus $s$ for the 2 different densities, $D_{\mathrm{r}}=62$ to 66 and $=80$ to $84 \%$, are compared in Fig. 8 . The diagonal dotted line distinguishes the regions above and below the groundwater level. For each of
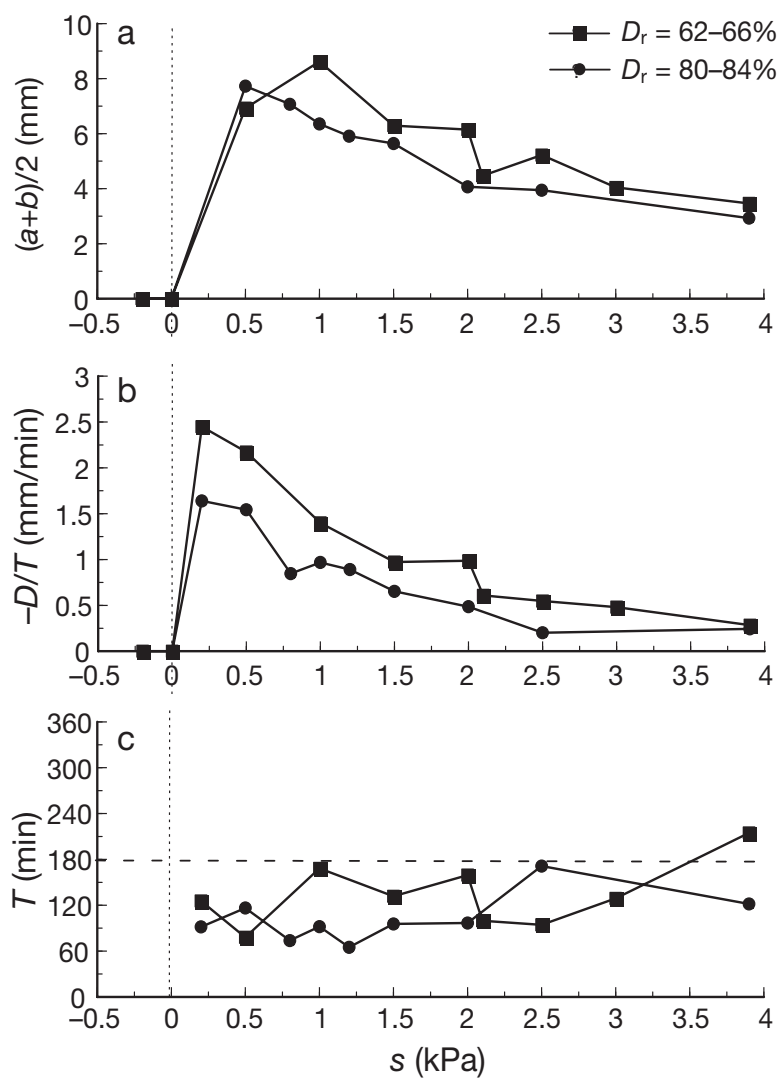

Fig. 7. Scopimera globosa. Comparison of the measured (a) sand ball diameters $((a+b) / 2)$, (b) burrowing velocities $(-D / T)$, and (c) burrow formation times $(T)$ versus suction $(s)$ for 2 different sediment relative densities: $D_{\mathrm{r}}=62$ to $66 \%$ and $D_{\mathrm{r}}=80$ to $84 \%$. Data shown in (a) represent the mean values plotted in Fig. 5

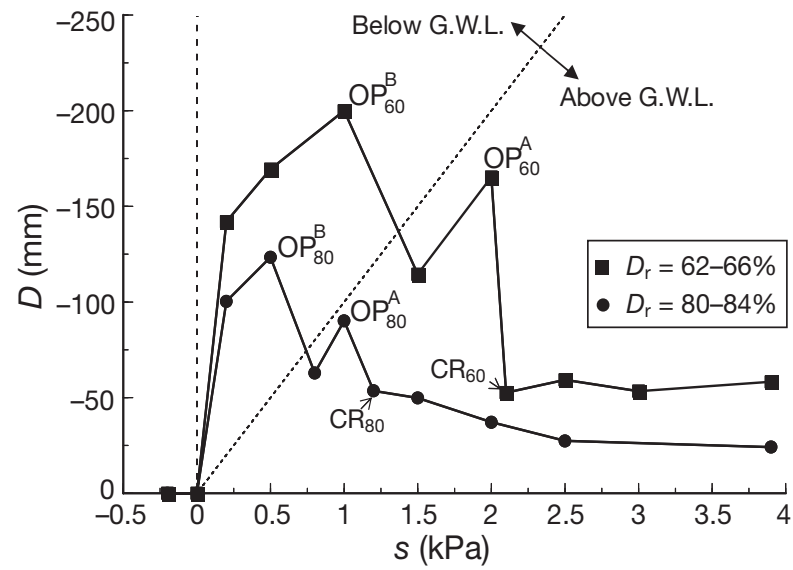

Fig. 8. Scopimera globosa. Comparison of measured final depths of burrows $(D)$ versus suction $(s)$ for 2 different sediment relative densities, $D_{\mathrm{r}}=62$ to $66 \%$ and $D_{\mathrm{r}}=80$ to $84 \%$. $\mathrm{OP}^{\mathrm{A}}$ and $\mathrm{OP}^{\mathrm{B}}$ : optimum geophysical states for the development of burrows above and below the groundwater level (G.W.L.), respectively. CR: critical geophysical state for development of burrows. Subscripts 60 and 80 stand for $D_{\mathrm{r}}=62$ to 66 and 80 to $84 \%$. Data shown represent the mean values plotted in Fig. 6

the densities, there were 2 peaks in $D$, representing 2 optimum states for the development of the burrows. One optimum state, $\mathrm{OP}^{\mathrm{B}}$, occurred below the groundwater level, and the other optimum state, $\mathrm{OP}^{\mathrm{A}}$, occurred above the groundwater level. $D$ then declined markedly with further increases in $s$. This gave rise to a critical state (CR) beyond which $D$ did not increase further. All of these states appeared at higher $s$ under the lower density $D_{\mathrm{r}}=62$ to $66 \%$.

\section{DISCUSSION}

The results of the field observations and burrowing experiments clearly indicate that $s$ and the relevant geophysical environmental conditions affected the burrowing performance of Scopimera globosa. To discuss the underlying mechanisms further, we present a conceptual model (Fig. 9). The crab has 2 distinctive regions of burrowing activity: above and below the groundwater level. When the crab burrows above the groundwater level, $s$ has 2 contrasting effects: it produces the effective cohesion that allows burrowing and governs the sand depth to which burrowing is physically possible; and it induces enhanced strength that makes burrowing more difficult. This trade-off gives rise to an optimum state $\mathrm{OP}^{\mathrm{A}}$ and a critical state $\mathrm{CR}$ of the $s$ for the development of the burrow above the groundwater level, as shown in Fig. 8. For the burrowing activity below the groundwater level, the crab uses a closed cavity containing entrapped air and the crab 


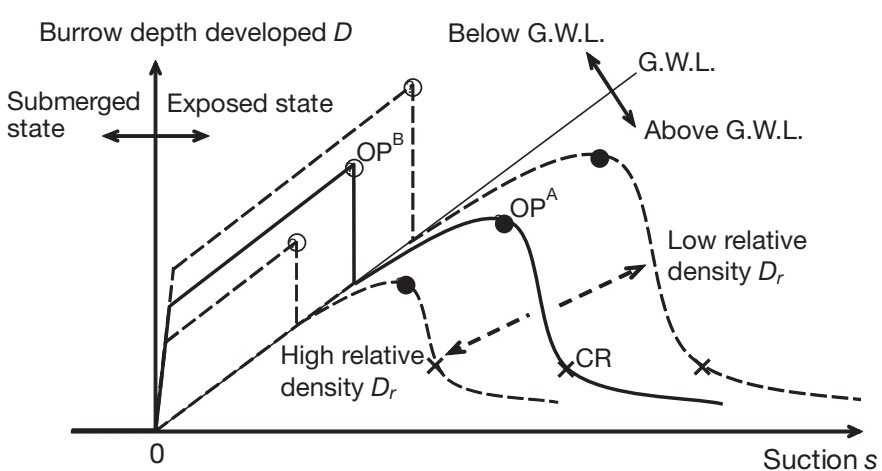

Fig. 9. Scopimera globosa. Conceptual model to account for the link between burrow development, and suction and related geoenvironmental conditions. $\mathrm{OP}^{\mathrm{A}}$ and $\mathrm{OP}^{\mathrm{B}}$ : optimum geophysical states for the development of burrows above and below the groundwater level (G.W.L.), respectively. CR: critical geophysical state for the development of burrows

itself. Burrowing proceeds below the groundwater level by an additional amount that depends on the sediment strength in the absence of $S_{\text {; }}$ in other words, on the relative density of the sediment (Fig. 9). As a result, there is an optimum $s$ state $\mathrm{OP}^{\mathrm{B}}$ for the development of the burrow below the groundwater level, as shown in Fig. 8. Burrowing performance is characterized by these 3 geophysical states $-\mathrm{CR}, \mathrm{OP}^{\mathrm{A}}$ and $\mathrm{OP}^{\mathrm{B}}$ - which manifest themselves at particular VSS and which are a function of both $s$ and $D_{\mathrm{r}}$ (see Appendix 1). This conceptual model is capable of consistently accounting for the observed crab responses, namely the threshold state, the 2 different optimum states, and the critical state of the $s$ and related geophysical environmental conditions for the development of the burrows.

Most of the intertidal crabs of the family Ocypodidae live in burrows as deep as $200 \mathrm{~mm}$ below the sediment surface (Wada 2000). This means that there was substantial variation in the observed range of burrow depths. The simulated geophysical environments that involved $s$, groundwater level, $D_{\mathrm{r}}$, and VSS were realistic in view of their distributions in the field (Sassa \& Watabe 2007). The present results demonstrate that the presence of $s$ is an essential threshold condition for a burrow to be formed. Since the fact that $s$ may or may not develop strongly depends on the local topographical features, the distributions of $s$ should be closely linked with the distributions of Scopimera globosa, which shows a preference for certain areas among the midlittoral zone where the sediment grain sizes are similar (Wada 2000).

Burrows need to be sufficiently deep in order to fulfill their functions. If the burrows are limited to the level of the uppermost sediment, say $\mathrm{z} \geq-50 \mathrm{~mm}$, the crabs would be readily exposed to risks such as surface transport, predators, and the direct rays of the sun. In fact, summer temperatures in such shallow depths may exceed the upper lethal limits of the crabs (Eshky et al. 1995). The critical geophysical state (CR) could generate such fatal situations, or the crabs would simply not select the sediments in that state. By contrast, the optimum geophysical states (OP) can facilitate the development of burrows. Such well-developed burrows are particularly important for some female crabs in their breeding cycle (Christy 1987).

One important prediction of recent studies (e.g. Dugan et al. 2004, Brazeiro 2005) related to the swash exclusion hypothesis (McLachlan et al. 1993) is that burrowing capability may determine which species of macroinfauna can successfully inhabit the intertidal zone. The present results clearly indicate that burrowing capability represents both burrowing speed and burrow development, both of which vary considerably with the $s$ state and the related geophysical environmental conditions. Hence, the natural selection of habitats of macroinfauna should depend not only on wave and swash conditions, but also on the physical states of the sediments. Furthermore, the present results indicate that, for a given species of macroinfauna, there exist suitable geoenvironmental conditions favorable to burrowing activity. Since burrowing capability varies markedly among species and by their body size (Dugan et al. 2000, Nel et al. 2001), the suitable geoenvironmental conditions may change accordingly, which could then contribute to the patterns of zonation and community structure in the intertidal sediments. The present study may provide a rational basis for the role of geophysics in ecology and stimulate future infaunal research in intertidal zones.

Acknowledgements. We gratefully acknowledge the helpful comments provided by 3 anonymous reviewers. We also thank T. Kuwae for discussions and his support in statistical analysis. This research was funded by the Ministry of Education, Culture, Sports, Science and Technology, Japan, under the grant-in-aid for scientific research (11776039 and 18360232).

\section{LITERATURE CITED}

Altevogt R (1955) Some studies on two species of Indian fiddler crabs, Uca marionis (Dana) and U. annulipes (Latr.). J Bombay Nat Hist Soc 52:702-716

Amos CL, Wagoner NAV, Daborn GR (1988) The influence of subaerial exposure on the bulk properties of fine-grained intertidal sediment from Minas Basin, Bay of Fundy. Estuar Coast Shelf Sci 27:1-13

Bear J (1979) Hydraulics of groundwater. McGraw-Hill Intl. Book Co., New York

Botto F, Iribarne O (2000) Contrasting effects of two burrowing crabs (Chasmagnathus granulata and Uca uruguayensis) on sediment composition and transport in estuarine environments. Estuar Coast Shelf Sci 51:141-151 
Brazeiro A (2005) Geomorphology induces life history changes in invertebrates of sandy beaches: the case of the mole crab Emerita analoga in Chile. J Mar Biol Assoc UK 85:113-120

Christy JH (1987) Female choice and the breeding behaviour of the fiddler crab Uca beebei. J Crustac Biol 7:624-635

Donn TE Jr, Els SF (1990) Burrowing times of Donax serra from the south and west coasts of South Africa. Veliger 33: 355-358

Dugan JE, Hubbard DM, Lastra M (2000) Burrowing abilities and swash behaviour of three crabs, Emerita analoga Stimpson, Blepharipoda occidentalis Randall and Lepidopa californica Efford (Anomura, Hippoidea), of exposed sandy beaches. J Exp Mar Biol Ecol 255: 229-245

Dugan JE, Jaramillo E, Hubbard DM, Contreras H, Duarte C (2004) Competitive interactions in macroinfaunal animals of exposed sandy beaches. Oecologia 139:630-640

Eshky AA, Atkinson RJA, Taylor AC (1995) Physiological ecology of crabs from Saudi Arabian mangrove. Mar Ecol Prog Ser 126:83-95

Icely JD, Jones DA (1978) Factors affecting the distribution of the genus Uca (Crustacea: Ocypodidae) on an East African shore. Estuar Coast Mar Sci 6:315-325

Koga T, Henmi Y, Murai M (1993) Sperm competition and the assurance of underground copulation in the sand-bubbler crab Scopimera globosa (Brachyura: Ocypodidae). J Crustac Biol 13:134-137

Kuwae T, Kibe E, Nakamura Y (2003) Effect of emersion and immersion on the porewater nutrient dynamics of an intertidal sandflat in Tokyo Bay. Estuar Coast Shelf Sci 57: 929-940

McGaw IJ (2005) Burying behaviour of two sympatric crab specices: Cancer magister and Cancer productus. Sci Mar 69:375-381

McLachlan A (1990) Dissipative beaches and macroinfauna communities on exposed intertidal sands. J Coast Res 6: $57-71$

McLachlan A, Jaramillo E, Donn TE, Wessels F (1993) Sandy beach macroinfauna communities and their control by the physical environment: a geographical comparison. J Coastal Res 15:27-38

Nel R, McLachlan A, Winter DPE (2001) The effect of grain size on the burrowing of two Donax species. J Exp Mar Biol Ecol 265:219-238

Sassa S, Watabe Y (2007) Role of suction dynamics in evolution of intertidal sandy flats: field evidence, experiments, and theoretical model. J Geophys Res 112 F01003, doi:10.1029/2006JF000575

Taylor DW (1948) Fundamentals of soil mechanics. John Wiley \& Sons, New York

Wada K (2000) Ecological sciences 11. Kyoto University (in Japanese)

Warner GF (1977) The biology of crabs. Paul Elek (Science Books), London

Zucker N (1977) Neighbor dislodgement and burrow-filling activity by male Uca muscica terpsichores: a spacing mechanism. Mar Biol 41:281-286

Appendix 1. Interrelationships between VSS, void state, and $s$

The interrelationships between vane shear strength (VSS), void state, and suction ( $s$ ) for the intertidal sandy sediment of the Banzu flat are shown in Fig. A1, adopted from Sassa \& Watabe (2007). VSS increases markedly with increasing $s$ and with increasing $D_{\mathrm{r}}$. By contrast, when $s$ is absent $(s<0)$, VSS depends only on the $D_{\mathrm{r}}$. In essence, there exists the relationship:

$$
\operatorname{VSS}=\operatorname{VSS}\left(s, D_{\mathrm{r}}\right)
$$

The above relationship can be used to analyze the observed crab responses. In Fig. 8, the critical state $\mathrm{CR}_{60}$ for $D_{\mathrm{r}}=62$ to $66 \%$ appeared at $s=2.1 \mathrm{kPa}$, and another critical state $\mathrm{CR}_{80}$ for $D_{\mathrm{r}}=80$ to $84 \%$ appeared at $s=1.2 \mathrm{kPa}$. These 2 different sets of $s$ and $D_{\mathrm{r}}$ gave rise to the same VSS, equal to $5.4 \mathrm{kPa}$, according to the function $\operatorname{VSS}=\operatorname{VSS}\left(s, D_{\mathrm{r}}\right)$. Similarly, the VSS determining the 2 different optimum states $\mathrm{OP}^{\mathrm{A}}$ and $\mathrm{OP}^{\mathrm{B}}$ were equal to $5 \mathrm{kPa}$ and $3 \mathrm{kPa}$, respectively, by comparing Figs. 8 \& A1.

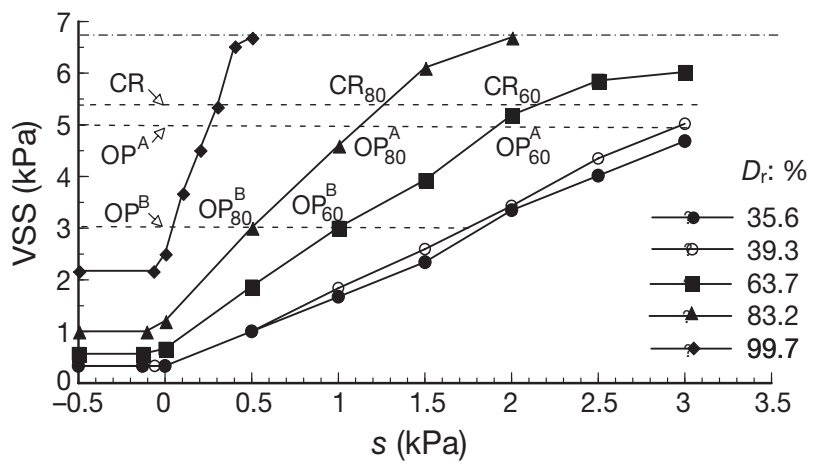

Fig. A1. Vane shear strength (VSS) versus suction (s) for 5 different states of sediment packing. Figure adopted from Sassa \& Watabe (2007); shows summary plots from the vane shear experiments performed on the intertidal sediment of the Banzu flat. $\mathrm{OP}^{\mathrm{A}}$ and $\mathrm{OP}^{\mathrm{B}}$ : optimum geophysical states for the development of burrows above and below groundwater level, respectively. CR: critical geophysical state for development of burrows. Subscripts 60 and 80 stand for $D_{\mathrm{r}}=62$ to 66 and 80 to $84 \%$. Dotted chain line represents the maximum measurable value of the apparatus used
Editorial responsibility: Otto Kinne, Oldendorf/Luhe, Germany
Submitted: June 6, 2006; Accepted: September 7, 2007

Proofs received from author(s): January 28, 2008 